\title{
Simplified Air Change Effectiveness Modeling
}

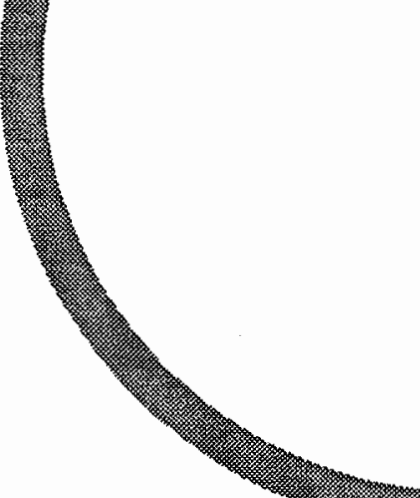

Brian A. Rock

Ren Anderson

National Renewable Energy Laboratory

Michael J. Brandemuehl

University of Colorado at Boulder

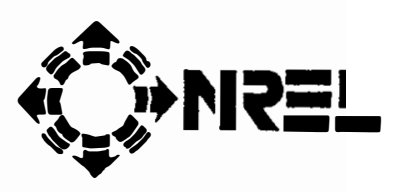

National Renewable Energy Laboratory

(formerly the Solar Energy Research Institute)

1617 Cole Boulevard

Golden, Colorado 80401-3393

A Division of Midwest Research Institute Operated for the U.S. Department of Energy under Contract No. DE-AC02-83CH10093 


\title{
On September 16, 1991 the Solar Energy Institute was designated a national laboratory, and its name was changed to the National Renewable Energy Laboratory.
}

\section{NOTICE}

This report was prepared as an account of work sponsored by an agency of the United States government. Neither the United States government nor any agency thereof, nor any of their employees, makes any warranty, express or implied, or assumes any legal liability or responsibility for the accuracy, completeness, or usefulness of any information, apparatus, product, or process disclosed, or represents that its use would not infringe privately owned rights. Reference herein to any specific commercial product, process, or service by trade name, trademark, manufacturer, or otherwise does not necessarily constitute or imply its endorsement, recommendation, or favoring by the United States government or any agency thereof. The views and opinions of authors expressed herein do not necessarily state or reflect those of the United States government or any agency thereof.

\author{
Printed in the United States of America \\ Available from: \\ National Technical Information Service \\ U.S. Department of Commerce \\ 5285 Port Royal Road \\ Springfield, VA22161 \\ Price: Microfiche A01 \\ Printed Copy $\mathrm{AO3}$
}

Codes are used for pricing all publications. The code is determined by the number of pages in the publication. Information pertaining to the pricing codes can be found in the current issue of the following publications which are generally available in most libraries: Energy Research Abstracts (ERA); Government Reports Announcements and Index (GRA and I); Scientific and Technical Abstract Reports (STAR); and publication NTIS-PR-360 available from NTIS at the above address. 


\section{Contents}

Page

List of Figures $\ldots \ldots \ldots \ldots \ldots \ldots \ldots \ldots \ldots \ldots \ldots \ldots \ldots \ldots \ldots \ldots \ldots \ldots \ldots \ldots$ iv

Terminology $\ldots \ldots \ldots \ldots \ldots \ldots \ldots \ldots \ldots \ldots \ldots \ldots \ldots \ldots \ldots \ldots \ldots \ldots \ldots$ vi

Nomenclature $\ldots \ldots \ldots \ldots \ldots \ldots \ldots \ldots \ldots \ldots \ldots \ldots \ldots \ldots \ldots \ldots \ldots \ldots \ldots \ldots$

Abstract $\ldots \ldots \ldots \ldots \ldots \ldots \ldots \ldots \ldots \ldots \ldots \ldots \ldots \ldots \ldots \ldots \ldots \ldots \ldots \ldots \ldots \ldots$ viii

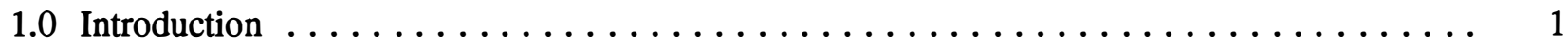

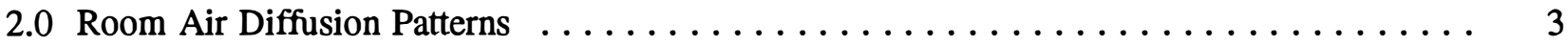

3.0 Occupancy in Two-Region Rooms $\ldots \ldots \ldots \ldots \ldots \ldots \ldots \ldots \ldots \ldots \ldots \ldots \ldots$

4.0 Relative Ventilation Performance $\ldots \ldots \ldots \ldots \ldots \ldots \ldots \ldots \ldots \ldots \ldots \ldots$

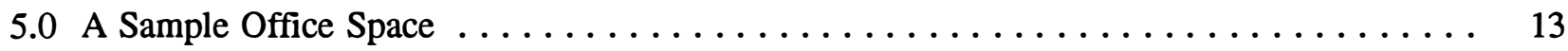

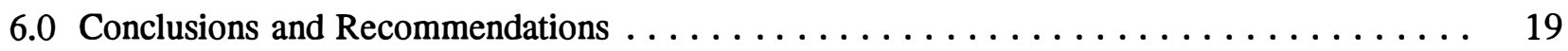

7.0 Acknowledgments $\ldots \ldots \ldots \ldots \ldots \ldots \ldots \ldots \ldots \ldots \ldots \ldots \ldots \ldots \ldots \ldots \ldots \ldots \ldots$

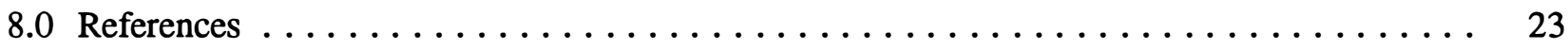




\section{List of Figures}

$\underline{\text { Page }}$

1-1 Terminology and abbreviations for the study of air flow

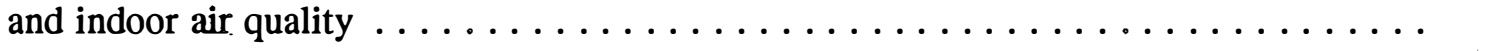

2-1 Entrainment flow in a room $\ldots \ldots \ldots \ldots \ldots \ldots \ldots \ldots \ldots \ldots \ldots \ldots \ldots \ldots \ldots \ldots \ldots$

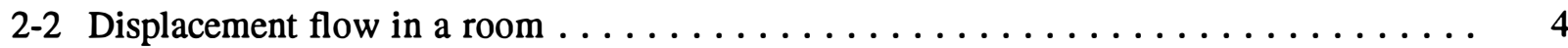

3-1 Entrainment flow case with vertical separation of the regions and the secondary region occupied

3-2 Entrainment flow case with vertical separation of the regions and the primary region occupied

3-3 Displacement flow case with vertical separation of the regions and

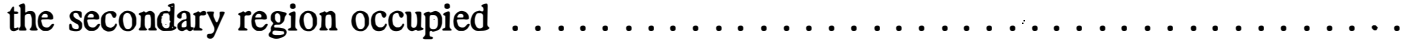

3-4 Displacement flow case with vertical separation of the regions and

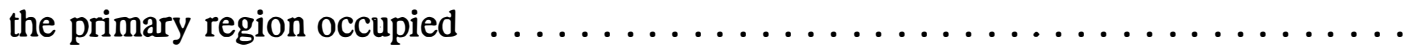

3-5 Entrainment flow case with horizontal separation of the regions and

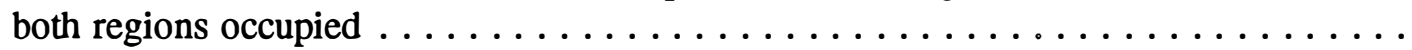

3-6 Displacement flow case with horizontal separation of the regions and both regions occupied

4-1 Layout of an entrainment flow system with recirculation and an

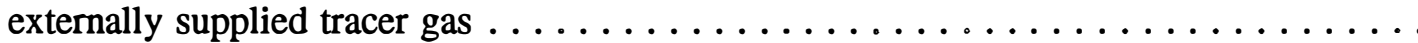

4-2 Laplace transform block diagram for the entrainment flow case with variable outside air fraction and transfer air fraction $\ldots \ldots \ldots \ldots \ldots \ldots \ldots$

4-3 Layout of the displacement flow system with recirculation and an

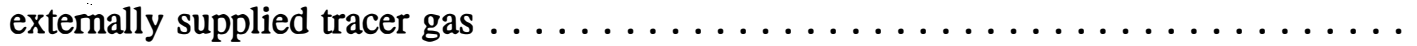

4-4 Laplace transform block diagram for the displacement flow case with variable outside air fraction and transfer air fraction $\ldots \ldots \ldots \ldots \ldots \ldots \ldots$

5-1 Generic layout of the apparent $\mathrm{ACH}$ effectiveness as compared to the percentage of outside air for the two-region displacement, complete mixing, and entrainment cases

5-2 Apparent $\mathrm{ACH}$ effectiveness $\left(\varepsilon_{A C H}\right)$ as a function of percentage of outside air and mixing coefficient $(\beta)$ for the sample two-region office space with $20 \%$ outside air at the design conditions 


\section{List of Figures (concluded)}

$\underline{\text { Page }}$

5-3 Apparent $\mathrm{ACH}$ effectiveness $\left(\varepsilon_{A C H}\right)$ as a function of percentage of outside air and mixing coefficient $(\beta)$ for the sample two-region office space with

5-4 Apparent $\mathrm{ACH}$ effectiveness $\left(\varepsilon_{A C H}\right)$ as a function of percentage of outside air and mixing coefficient $(\beta)$ for the sample two-region office space with



5-5 Apparent $\mathrm{ACH}$ effectiveness $\left(\varepsilon_{A C H}\right)$ as a function of outside air flow rate for the sample two-region office space with $100 \%$ outside air

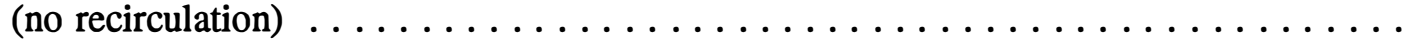




\section{Terminology}

Air: The atmosphere; The mixture of invisible, odorless, tasteless [and harmless] gases (nitrogen, oxygen, and others) that surround the earth [including water vapor, but not including contaminants] [ASHRAE 1991].

Air Change Effectiveness: A group of indoor air quality measures used to determine the effectiveness of ventilation air delivery.

Contaminant: An unwanted airborne constituent that may reduce the acceptability of the air [ASHRAE 1989b].

Displacement Flow: A piston- or plug-like room air motion pattern.

Entrainment Flow: A room air motion pattern that depends on the entrainment of room air into a jet.

Fresh Air: Has the same definition as outside air. "Fresh" air may contain an unacceptable amount of contaminants.

Outside Air: Air taken from the external atmosphere and, therefore, not previously circulated through the [air diffusion] system [ASHRAE 1989b].

Recirculated Air: Air removed from the conditioned space and intended for reuse as supply air [ASHRAE 1989b].

Return Air: Air removed from a space to be .. recirculated or exhausted [ASHRAE 1989b].

Supply Air: That air delivered to the conditioned space and used for ventilation, heating, cooling, humidification, or dehumidification [ASHRAE 1989b].

Transfer Air: The movement of indoor air from one space [or region] to another [ASHRAE 1989b].

Ventilation Air: That portion of the supply air that is [outside] air plus any recirculated air that has been treated [for creating or] maintaining acceptable indoor air quality [ASHRAE 1989b].

Ventilation Effectiveness: A group of indoor air quality measures used to determine the effectiveness of internally generated pollutant removal by an air distribution system. 


\section{Nomenclature}

$A C H=$ air changes per hour

$C=$ concentration of a pollutant, $\mathrm{lbm} / \mathrm{ft}^{3}$ or $\mathrm{mg} / \mathrm{L}$

$Q=$ volumetric air flow rate, $\mathrm{ft}^{3} / \mathrm{min}(\mathrm{CFM})$ or $\mathrm{L} / \mathrm{s}$

$s \quad=$ Laplace domain variable

$t_{\text {age }}=$ local age-of-air, $\min$ or $\mathrm{s}$

$V_{S}=$ nondimensional secondary region-to-total volume fraction (eq. 1)

$X_{o a}=$ outside air fraction

$X_{t a}=$ transfer air fraction (eq. 3)

Greek

$\beta=$ Sandberg's mixing coefficient or coupling factor (eq. 2)

$\varepsilon \quad=$ air change effectiveness

$\varepsilon_{A C H}=$ apparent $\mathrm{ACH}$ effectiveness (eq. 7)

$\tau=$ time constant, min or $s$

$\tau_{A}=$ air change time constant, min or $\mathrm{s}$

$\tau_{N}=$ nominal time constant, min or $\mathrm{s}$

Subscripts

$c a=$ recirculated air

ea $=$ exhaust air

$o a=$ outside air

$o a, 62=$ minimum required ASHRAE Standard 62-89 outside air

$P \quad=$ primary mixing region

$r a \quad=$ return air

$S \quad=$ secondary mixing region

$s a=$ supply air

ta $=$ transfer air 


\begin{abstract}
This paper describes recent progress in developing practical air change effectiveness modeling techniques for the design and analysis of air diffusion in occupied rooms. The ultimate goal of this continuing work is to develop a simple and reliable method for determining heating, ventilating, and air-conditioning (HVAC) system compliance with ventilation standards. In the current work, simplified two-region models of rooms are used with six occupancy patterns to find the air change effectiveness. A new measure, the apparent $\mathrm{ACH}$ effectiveness, yields the relative ventilation performance of an air diffusion system. This measure can be used for the prediction or evaluation of outside air delivery to the occupants. The required outside air can be greater or less than that specified by ventilation standards such as ASHRAE Standard 62-89.
\end{abstract}




\subsection{Introduction}

The National Renewable Energy Laboratory (NREL), in cooperation with the University of Colorado at Boulder (CU), is investigating ways to evaluate air flow in rooms and air-handling systems. Part of the ongoing research at NREL/CU includes developing measures and techniques that will ensure compliance with American Society of Heating, Refrigerating, and Air-Conditioning Engineers (ASHRAE) ventilation standards. ASHRAE Standard 62-89 requires a certain amount of ventilation air (CFM/person or $\mathrm{L} / \mathrm{s}$-person) to be delivered to the occupants of a building [ASHRAE 1989b]. Standard 62-89 does not adequately address the issue of whether the air being supplied to a room reaches the occupied space. This problem, called the air change effectiveness, and a solution approach are addressed in this paper. Although applied to U.S. design practices, the method presented in this paper may be extended to other ventilation approaches.

Figure 1-1 shows ASHRAE terminology for air flows in a system and some suggested terminology and abbreviations for studying these air flows. Some examples of terminology used for "outside air" are "fresh air" and "ventilation air." The term "fresh air" is not suitable because it implies that the air in the surrounding environment is always of acceptable quality. "Ventilation air" is used in Standard 62-89 to mean either outside air or suitably treated recirculated air. The use of the term "outside air" eliminates these ambiguities and is used in this paper. If the outside air is not of suitable quality, it and/or the recirculated air must be treated to create suitable ventilation air.

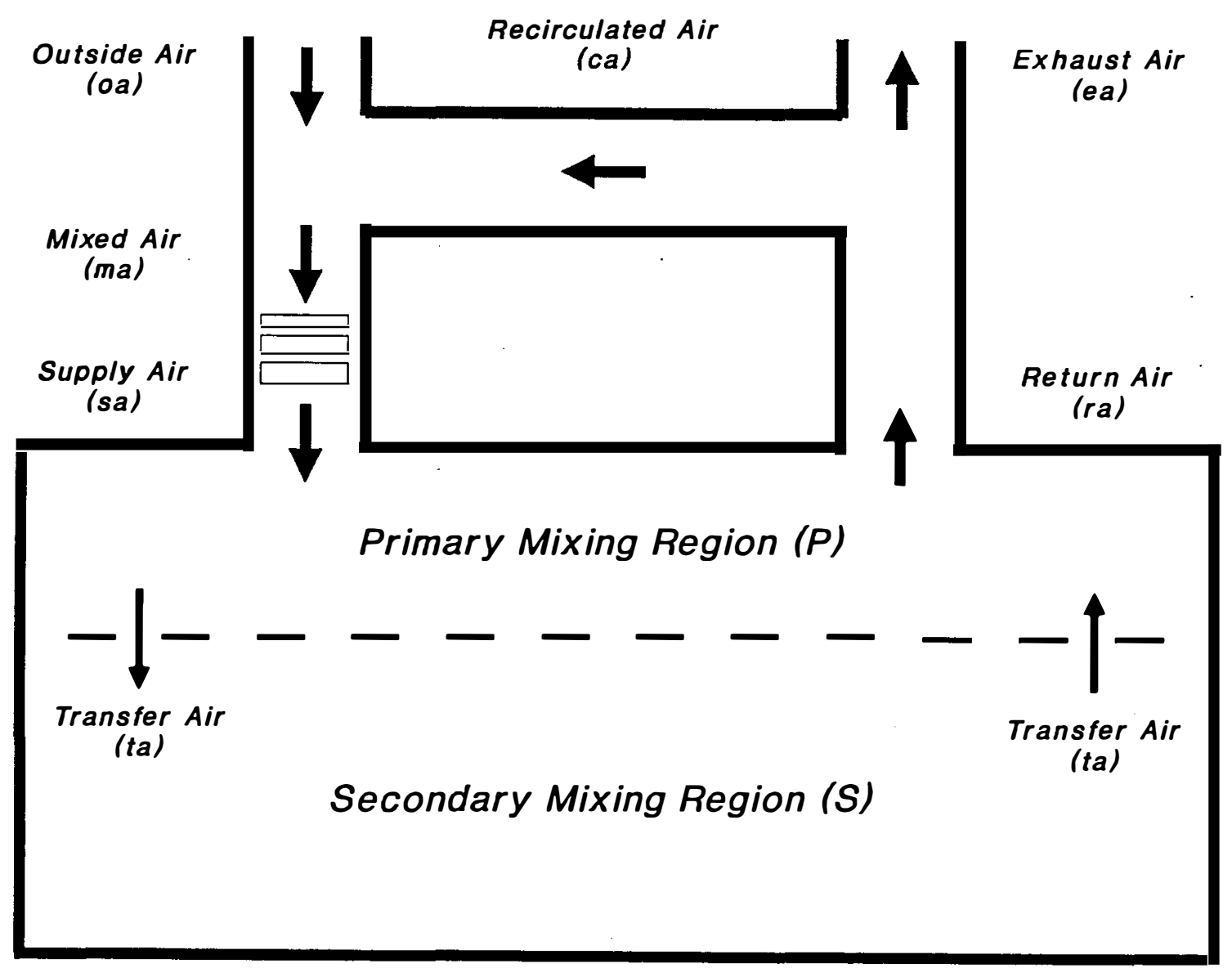

Figure 1-1. Terminology and abbreviations for the study of air flow and indoor air quality 
This study is limited to the evaluation of two-region models of room air flow. Previously, when tworegion mixing models were used for indoor air quality (IAQ) studies, the room was divided into an "occupied zone" and a "ceiling zone." A "zone" has a special meaning in heating, ventilating, and airconditioning (HVAC) studies, so a different term "region" is used in this study. In the Laplace transform/block diagram (LTBD) method [Rock et al. 1991a], these regions are completely mixed parts of a room or zone. For two-region room models, the terminology "primary mixing region" and "secondary mixing region" recognizes that these portions of a room may or may not be occupied and may have different mixing characteristics or flow patterns. 


\subsection{Room Air Diffusion Patterns}

The ventilation air flow rates specified in ASHRAE Standard 62 assume that rooms are completely mixed. With complete mixing, the supply air and contaminants are instantly and evenly distributed throughout a room. Anderson and Mehos [1988] showed that flow patterns in rooms can be highly nonuniform. The two nonuniform flow patterns addressed in this paper are shown in Figures 2-1 and 2-2. The flow pattern depicted in Figure 2-1 is created by the entrainment of room air into the supply air jet. This flow arrangement has been called "short-circuiting flow," "bypass flow," "conventional flow," "mixing system," or "ceiling-based system." None of these terms adequately describe the physical problem. A new term introduced in this study is "entrainment flow." This term recognizes that the flow pattern is created primarily by the entrainment of room air into a jet. The entrainment of the jet is dependent on the diffuser, room characteristics, and system operation.

When air flows in a piston-like manner through a room, it is usually called "plug" or "displacement" flow. The room depicted in Figure 2-2 has underfloor supply and ceiling-based return, both with many openings so that the air sweeps from bottom to top. Although most entrainment flow air diffusion systems are known to provide good thermal comfort and mixing, the performance of displacement flow air diffusion systems is still being examined. Seppänen et al. [1989] have reported that displacement systems can yield excellent air quality and thermal comfort.

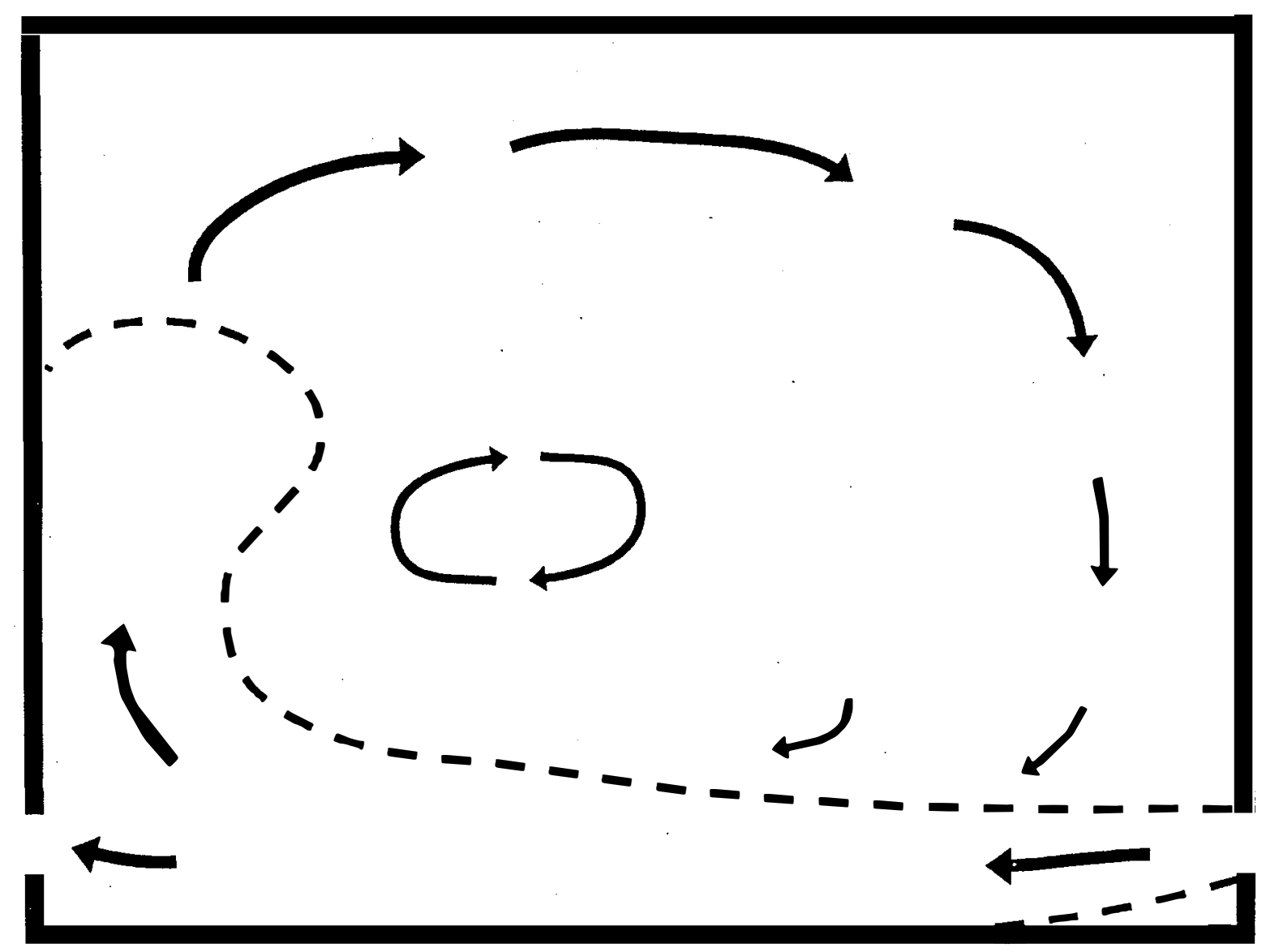

Figure 2-1. Entrainment flow in a room 


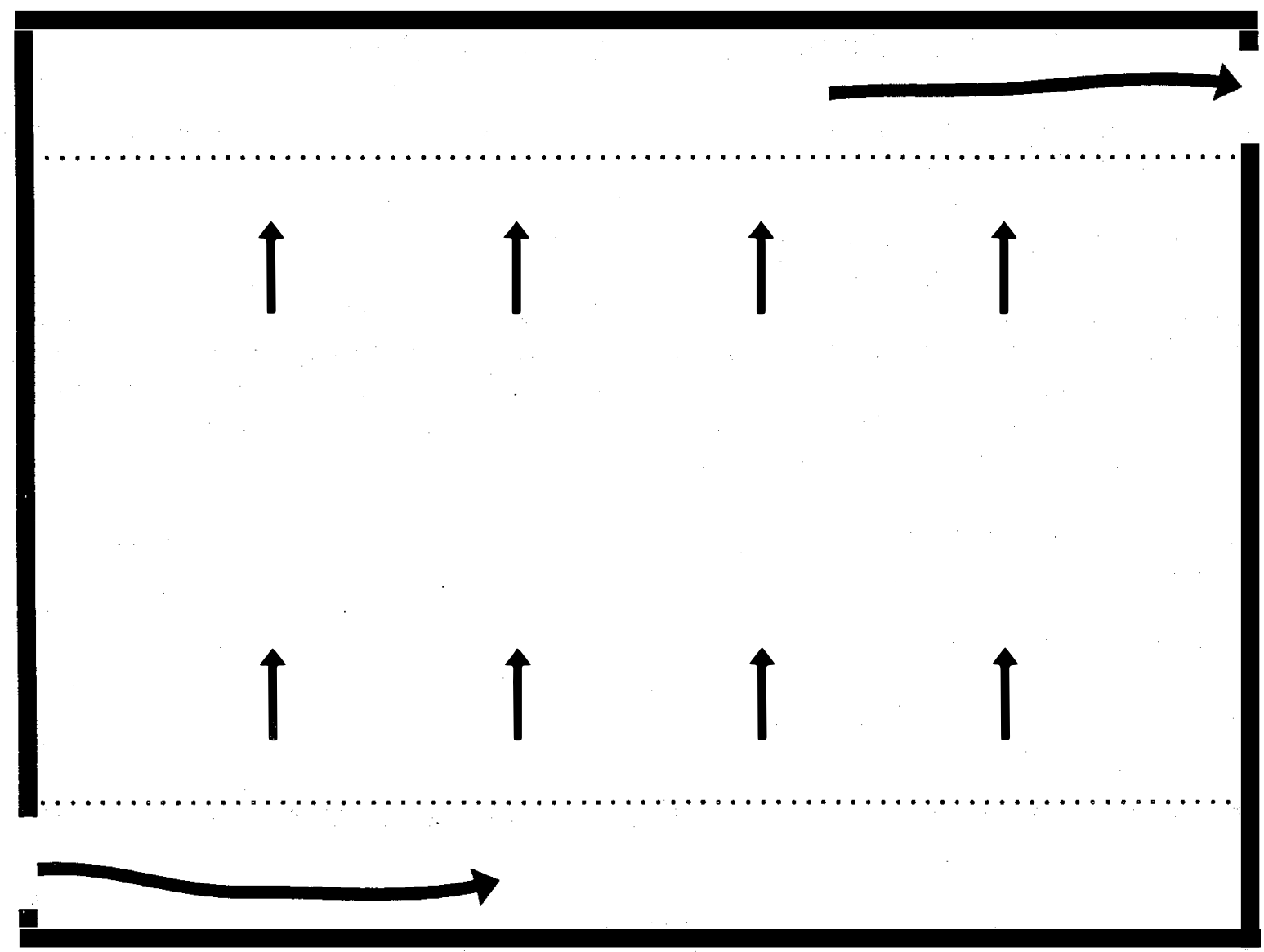

Figure 2-2. Displacement flow in a room 


\subsection{Occupancy in Two-Region Rooms}

Using a two-region model for a room or a zone [Sandberg 1981; Skåret and Mathisen 1983; Janssen 1984], there are six possible combinations of region layout and occupancy. These six geometries are shown in Figures 3-1 through 3-6. The two flow patterns shown in Figures 2-1 (entrainment flow) and 2-2 (displacement flow) can be approximated with two-region models. The two regions are defined by their volumes and their orientation with respect to the flow field. In the following models, the secondary region-to-total volume fraction $\left(V_{S}{ }^{*}\right)$ is an independent parameter. $V_{S}{ }^{*}$ is

$$
\mathbf{V}_{S}^{*}=\frac{\mathbf{V}_{S}}{V_{S}+V_{P}}
$$

where $V_{S}$ is the secondary region volume and $V_{P}$ is the primary region volume. In the entrainment flow two-region model, the two completely mixed regions of the model are arranged so that the supply air enters and return air leaves from the primary mixing region only. The secondary mixing region receives air only through the movement of air across the boundary between regions (transfer air). This movement of air is caused by the entrainment of air into the supply air jet. In the displacement flow two-region model, the regions are arranged so that the supply air enters the primary mixing region and the return air leaves the room from the secondary mixing region. A completely mixed room or zone is a special case of both the entrainment and displacement cases where the mixing coefficient ( $\beta$ ) [Sandberg 1981] is infinity or the transfer air fraction $\left(X_{t a}\right)$ [Rock et al. 1991a] is one. $\beta$ and $X_{t a}$ are defined for the tworegion models as:

$$
\begin{gathered}
\beta \equiv \frac{Q_{t a}}{Q_{s a}}, \quad 0 \leq \beta \leq \infty \\
X_{t a} \equiv \frac{Q_{t a}}{Q_{s a}+Q_{t a}}, \quad 0 \leq X_{t a} \leq 1 \\
\beta=\frac{X_{t a}}{1-X_{t a}} .
\end{gathered}
$$

These related values, $\beta$ and $X_{t a}$, are a second independent parameter used in the models found later in this paper. The authors are investigating simple methods to evaluate the independent parameters of the models. One method uses diffuser performance data that exists for a variety of applications. From the ASHRAE Handbook chapter on space air diffusion [ASHRAE 1989a], the entrainment ratio is

$$
\frac{\mathbf{Q}_{\mathbf{x}}}{\mathbf{Q}_{\mathrm{O}}}=\frac{2 * \mathrm{X}}{\mathbf{K}^{\prime} * \sqrt{\mathbf{A}_{0}}} \text {. }
$$

The mixing coefficient compared to the entrainment ratio is

$$
\beta=\frac{Q_{t a}}{Q_{s a}}=\frac{Q_{x}-Q_{0}}{Q_{0}}=\frac{Q_{x}}{Q_{0}}-1 .
$$

This promising method defines the region volumes and location of the regions as well. For example, for an isothermal jet created by a round diffuser, the value of the mixing coefficient has been found to be about 10 to 20 for throws of 15 to 25 feet (4.6 to 7.6 meters). Using the geometry of the jet and the room and the occupancy pattern, the volume fractions and mixing region locations can be found. 


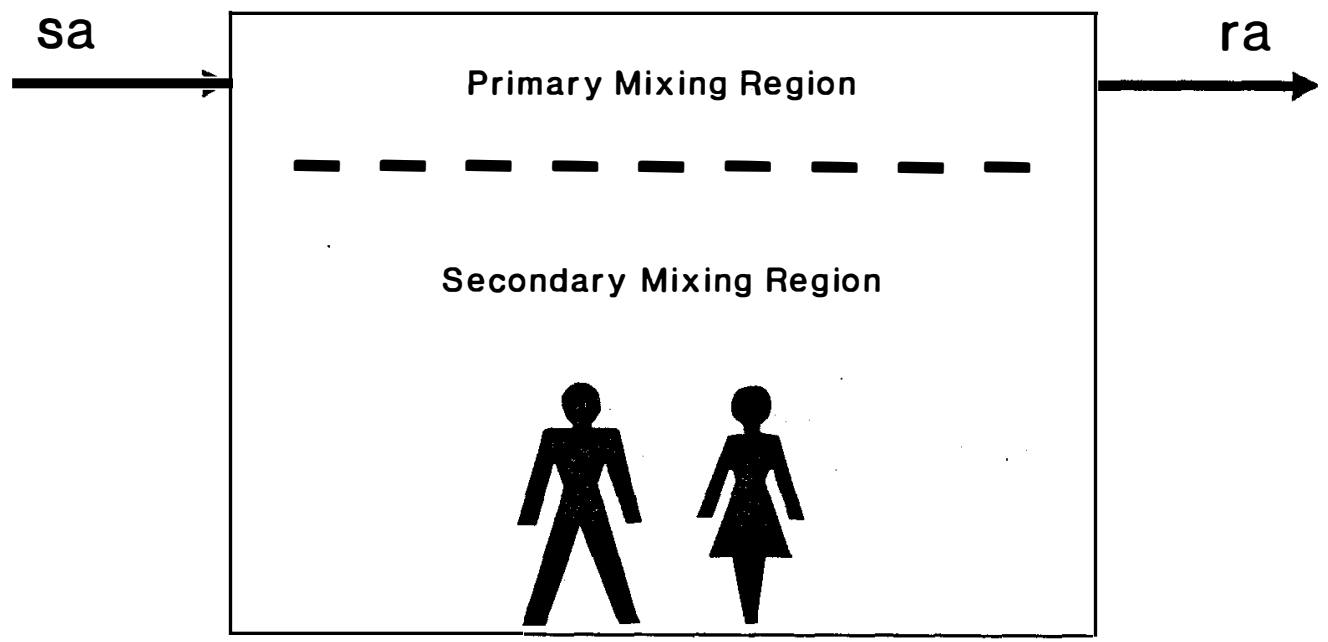

Figure 3-1. Entrainment flow case with vertical separation of the regions and the secondary region occupied

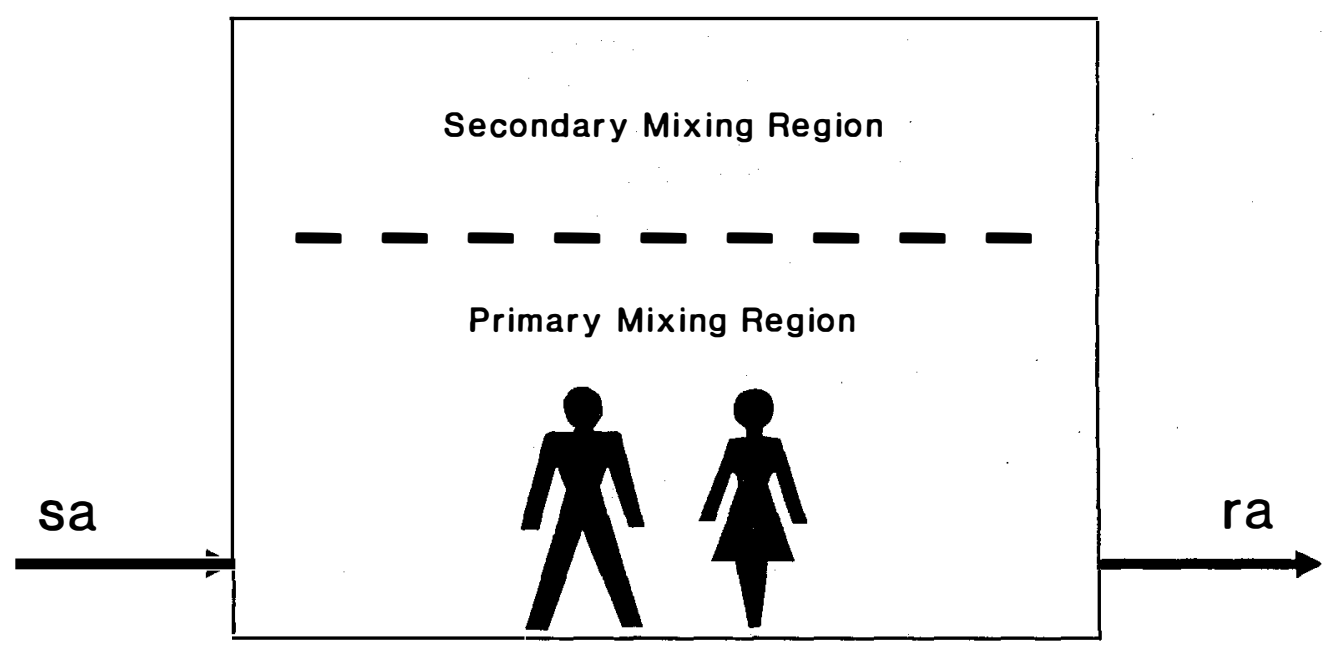

Figure 3-2. Entrainment flow case with vertical separation of the regions and the primary region occupied

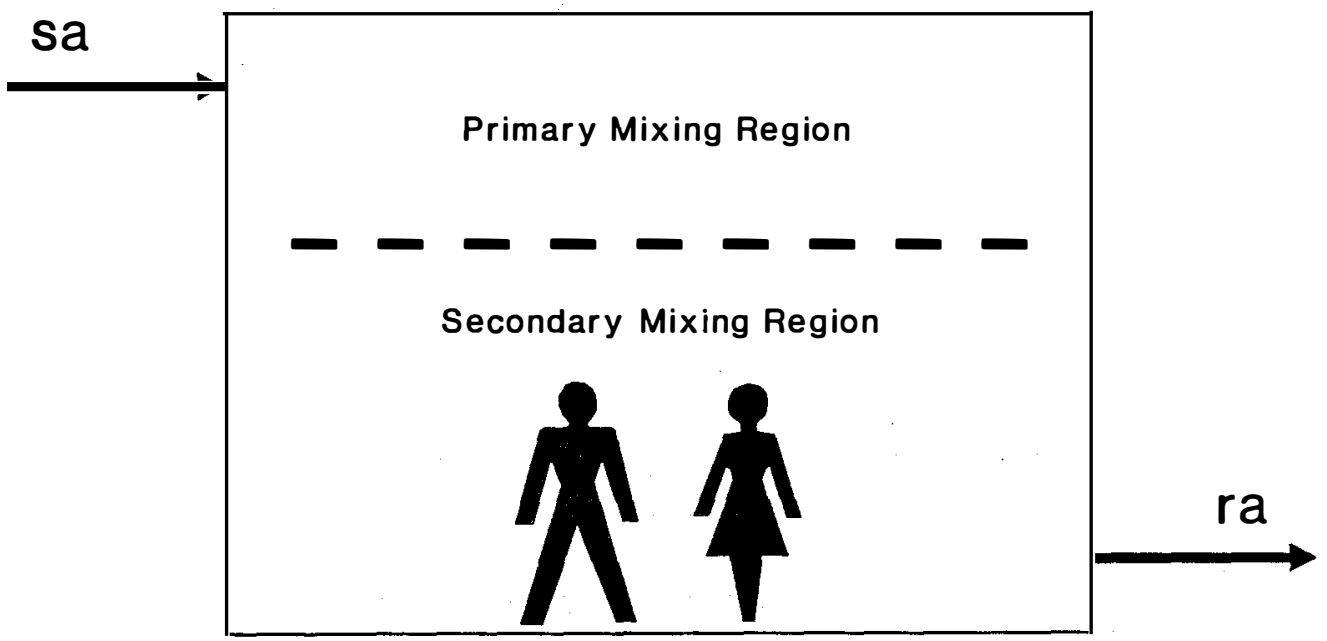

Figure 3-3. Displacement flow case with vertical separation of the regions and the secondary region occupied

6 


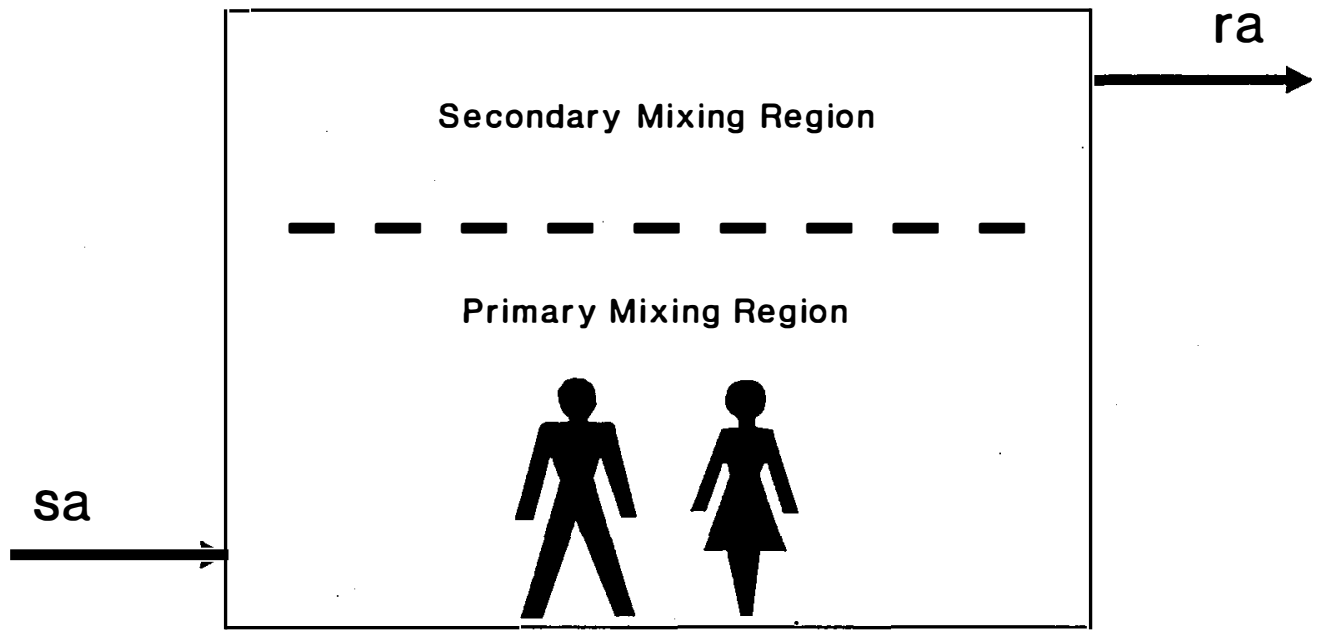

Figure 3-4. Displacement flow case with vertical separation of the regions and the primary region occupied

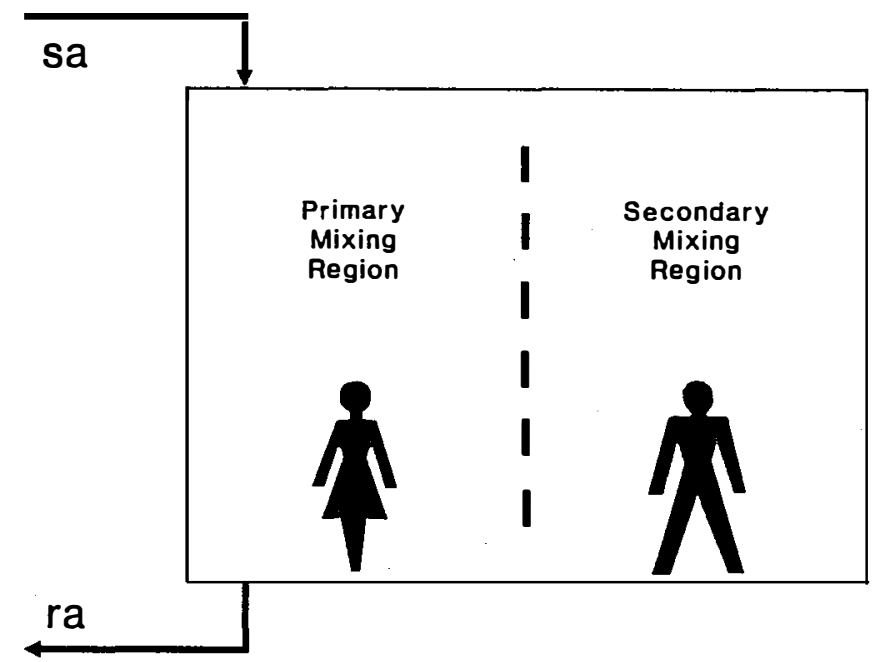

Figure 3-5. Entrainment flow case with horizontal separation of the regions and both regions occupied

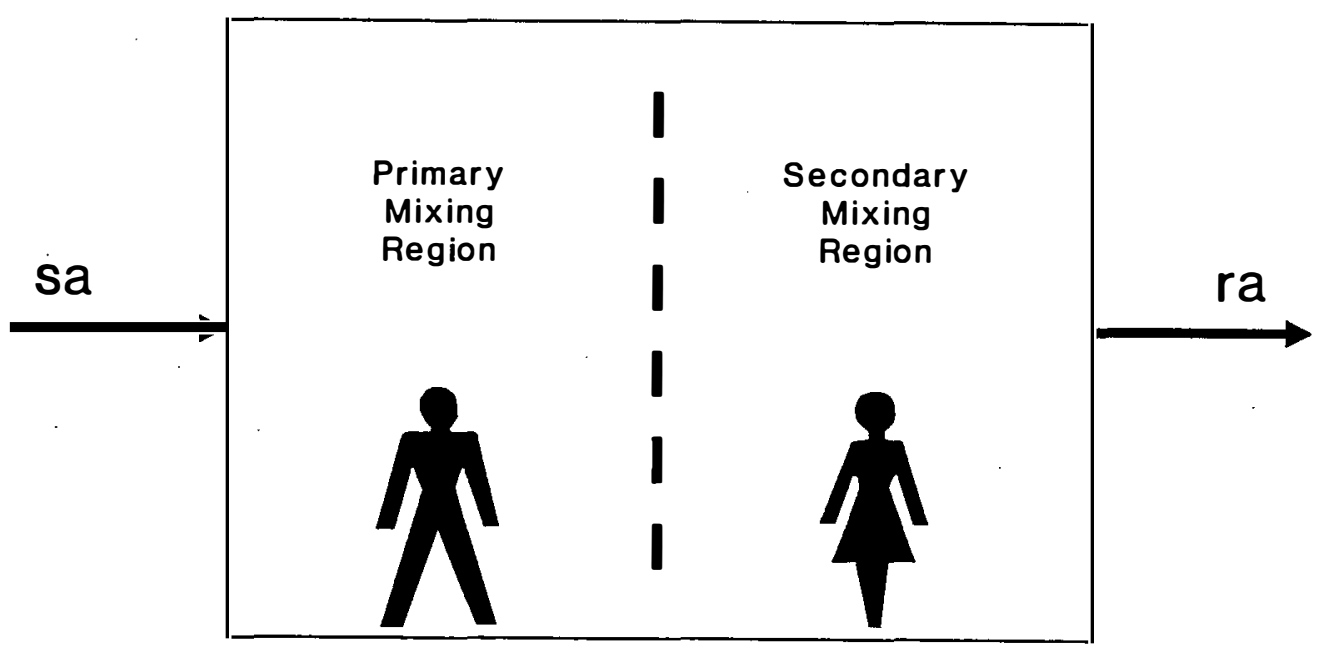

Figure 3-6. Displacement flow case with horizontal separation of the regions and both regions occupied 
Three possibilities exist for the location of room occupants in respect to the mixing regions. The occupants may be in the primary mixing region, the secondary mixing region, or both. In these ways the "occupied zone" is either or both of the mixing regions. The mixing regions may be oriented horizontally or vertically. Figure 3-1 shows the entrainment flow case that can model many U.S. office spaces. Ceiling-mounted supply air diffusers and return air grilles with the occupants in the secondary mixing region of the room can provide high levels of performance. Poorly applied air distribution systems with this geometry have ventilation problems if the mixing coefficient or transfer air fraction is unusually low. Figure 3-2 shows an entrainment flow case that models low-sidewall or floor-mounted diffusers and grilles so that the occupants are in the primary mixing region.

Figure 3-3 depicts a displacement flow case where the supply air is introduced at the top of the room and the return air is withdrawn at the bottom of the room. The occupants are located in the secondary mixing region. This geometry is very similar to that shown in Figure 3-1 except that the return air grille has been moved from the primary to the secondary region. Figure 3-4 depicts the displacement flow case with the occupants in the primary mixing region and the supply air introduced at or near the floor level. As with the geometry in Figure 3-2, the abatement of drafts is an important consideration in the design of a space with this flow arrangement.

Figures 3-5 and 3-6 show the entrainment and the displacement flow cases where both mixing regions are occupied. These situations suggest that if the two-region models are to be used for design or evaluation purposes, the region with the worst performance should be the limiting case. For both geometries shown in Figures 3-5 and 3-6, the worst ventilation performance appears in the secondary mixing regions. 


\subsection{Relative Ventilation Performance}

ASHRAE Standard 62-89 specifies that a minimum of 20 CFM $(9.44 \mathrm{~L} / \mathrm{s})$ ventilation air per person be delivered to the occupants of an office space. If the delivery of this ventilation air to a completely mixed room is used as the benchmark of performance, air distribution better or worse than complete mixing can be given a rating. The rating measure used in this paper is the "apparent ACH effectiveness $\left(\varepsilon_{A C H}\right)$," which uses the age-of-air approach. This measure is the ratio of the minimum nominal time constant specified using ASHRAE Standard 62-89 flow rates $\left(\tau_{o a, 62}\right)$ to the local age-of-air $\left(t_{\text {age }}\right)$. $\varepsilon_{A C H}$ is also equal to the ratio of the apparent local air change rate $(A C H)$ to the minimum outside air change rate $\left(A C H_{o a, 62}\right)$ specified using Standard 62-89, or

$$
\epsilon_{\mathrm{ACH}}=\frac{\tau_{\mathrm{OQ}, 62}}{\mathrm{t}_{\mathrm{age}^{\prime}}}=\frac{\mathrm{ACH}}{\mathrm{ACH}_{\mathrm{0Q,62}}}
$$

The apparent $\mathrm{ACH}$ effectiveness is a local measure that may be evaluated for any point in a room. For a completely mixed room, $\varepsilon_{A C H}$ is one when the Standard 62 design amount of outside air is being brought into the building. The apparent $\mathrm{ACH}$ effectiveness may be evaluated for part of a room such as the occupied region. If an occupied region of a room had an apparent $\mathrm{ACH}$ effectiveness below one, it would fail to meet Standard 62-89. Air change effectiveness depends strongly on the total system design and operation. For the same external conditions, the apparent $\mathrm{ACH}$ effectiveness for a displacement-type flow can be greater than that for complete mixing. The apparent $\mathrm{ACH}$ effectiveness of an entrainmenttype flow can be less than that for complete mixing. The $\varepsilon_{A C H}$ is affected by external conditions such as outside air flow rate and total supply air flow rate. A low-performance (low mixing coefficient) air distribution system can deliver high air change effectiveness if the outside air flow rate and recirculation rate are specified correctly at the design stage, or adjusted correctly at the commissioning stage. Both variable air volume (VAV) and constant air volume (CAV) systems should be evaluated with the outside air and mixing box dampers at the minimum air flow positions for occupied periods.

The LTBD method can be used to evaluate the age-of-air and the apparent ACH effectiveness for singleand multiple-region models. Two-region models are examined in this paper. Figures 4-1 and 4-3 show the layouts and Figures 4-2 and 4-4 show the Laplace transform block diagrams for the two-region entrainment and displacement flow cases. These geometries and models allow a variable transfer air fraction $\left(X_{t a}\right)$ and the potential for recirculation of part of the return air. The degree of recirculation is described by the outside air fraction $\left(X_{o a}=Q_{o d} / Q_{s a}\right)$. The LTBD method is a classical analysis technique for control and electrical systems and has recently been extended by the authors to the study of indoor air quality. Blocks, transfer functions, distribution points, and flow merges are laid out to model the physical problem. Application of the LTBD method to two-region problems yields two slightly different mathematical models for the entrainment and the displacement cases. For age-of-air calculations, a stepchange in concentration is applied to the outside air intake of the models. A detailed explanation of the LTBD method and models is available in two papers by Rock et al. [1991a;b] and in Rock [1992].

The results from the LTBD models can be used for the design of ventilation systems. With measurements made in existing spaces, the LTBD model results can also be used to determine compliance with air change effectiveness standards. A computer code using the rapidly solved LTBD models can evaluate

various geometries and variables. An understanding of the LTBD modeling approach is not necessary to use the two-region apparent ACH effectiveness method. 

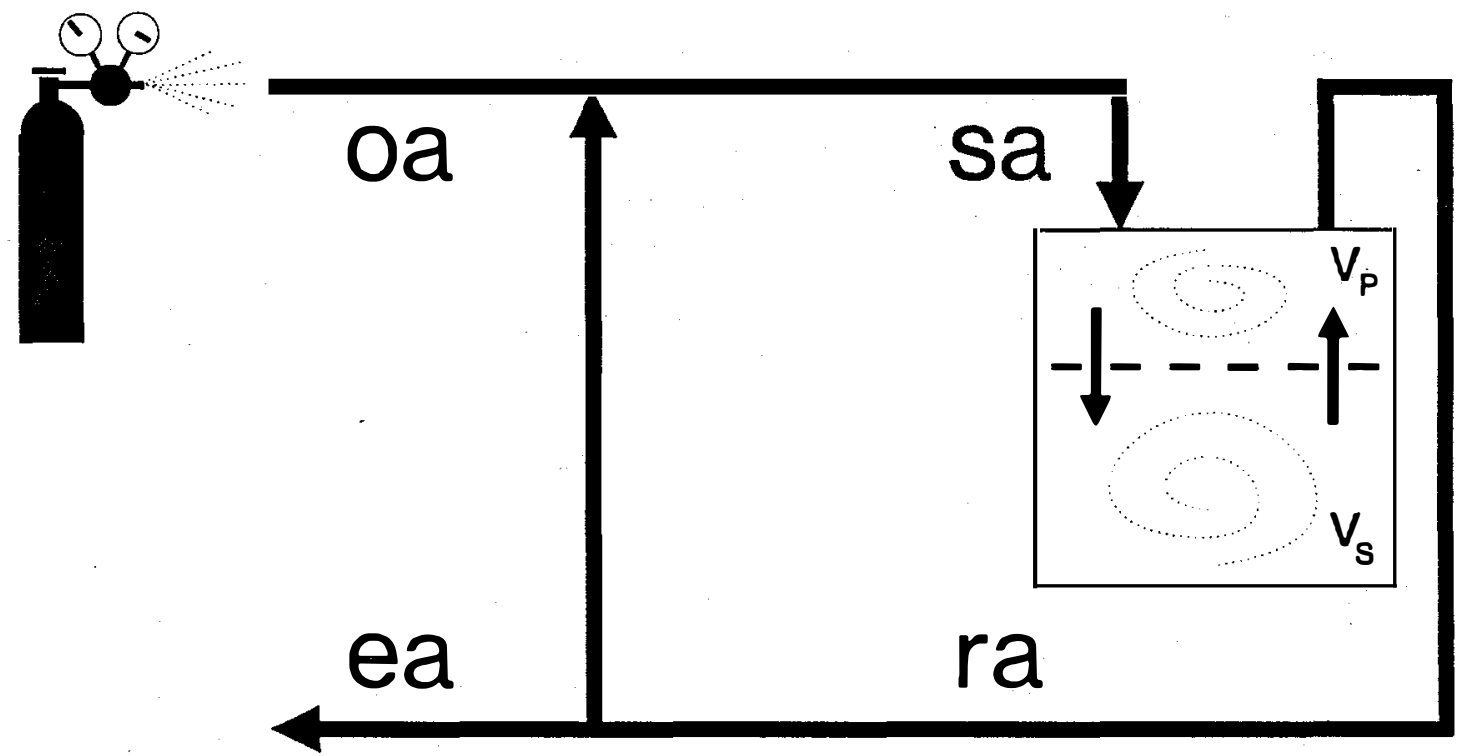

Figure 4-1. Layout of an entrainment flow system with recirculation and an externally supplied tracer gas

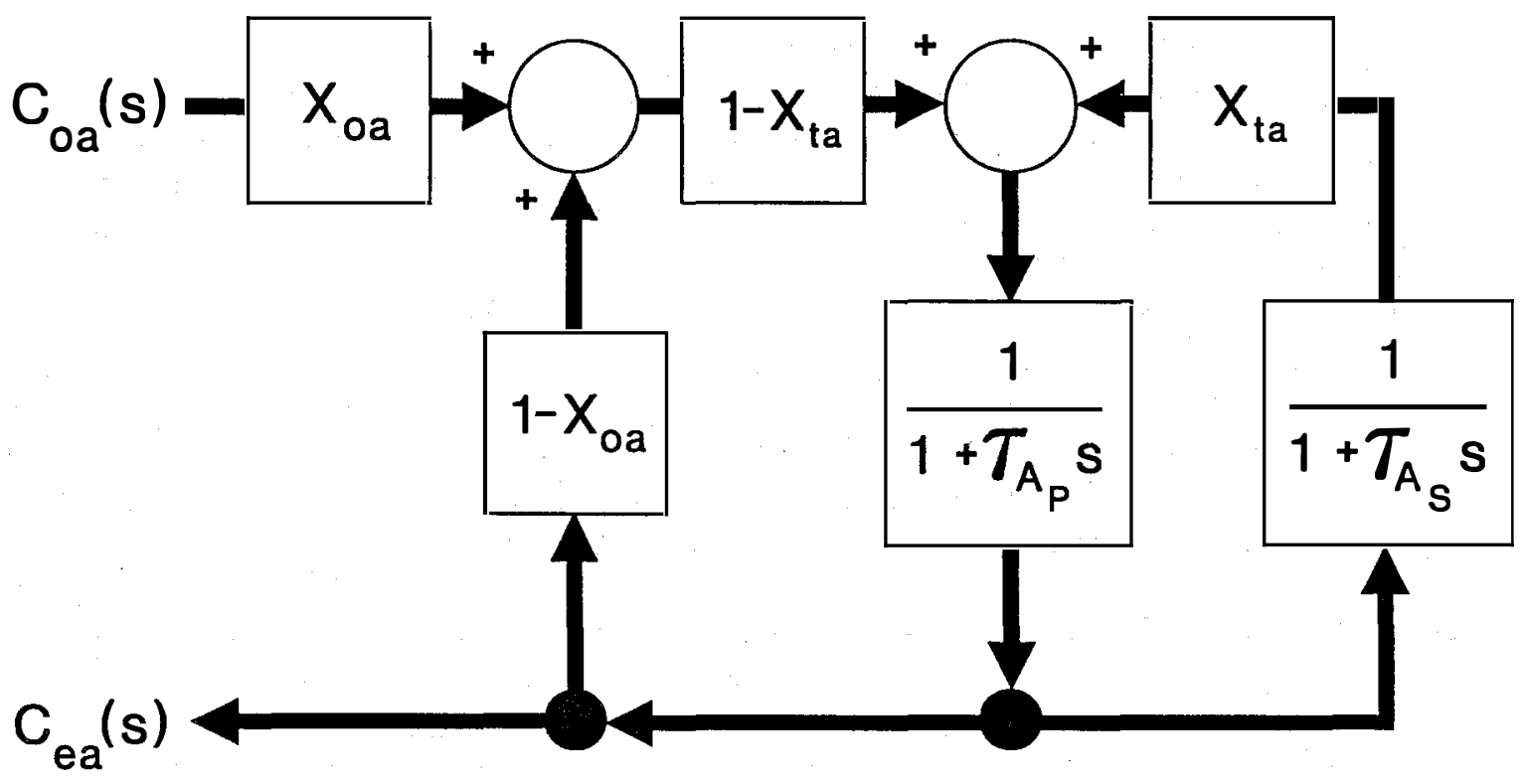

Figure 4-2. Laplace transform block diagram for the entrainment flow case with variable outside air fraction and transfer air fraction 


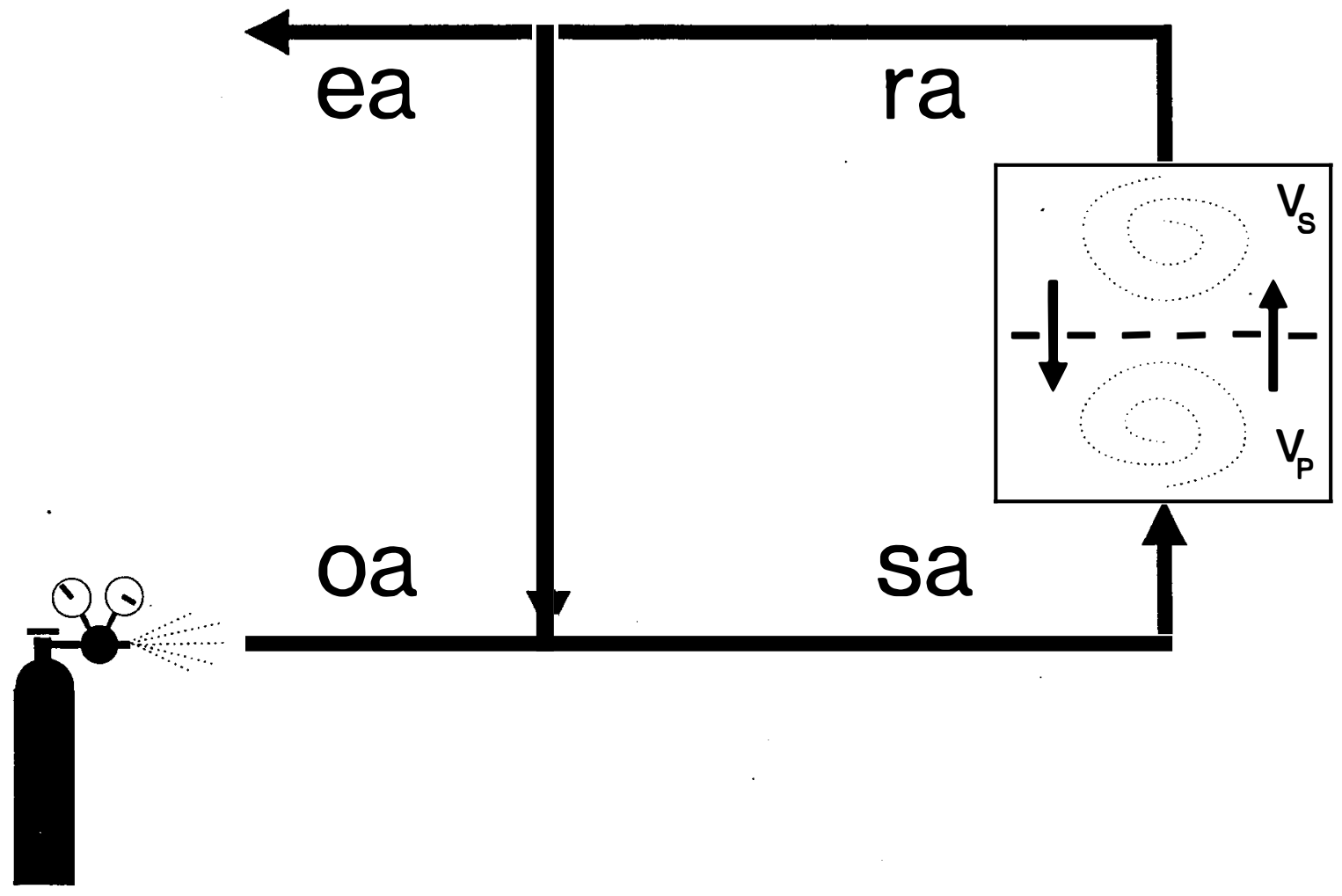

Figure 4-3. Layout of the displacement flow system with recirculation and an externally supplied tracer gas

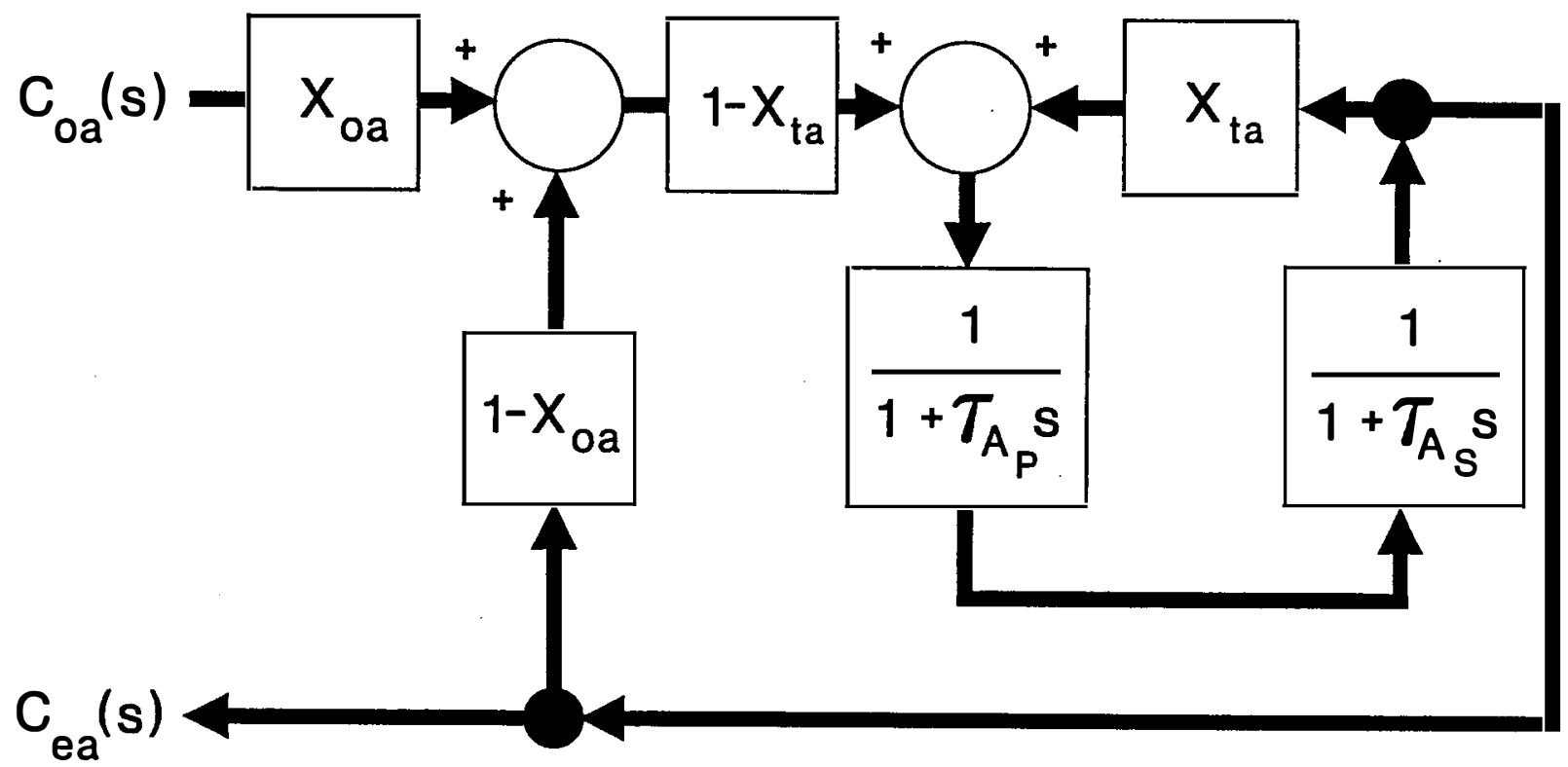

Figure 4-4. Laplace transform block diagram for the displacement flow case with variable outside air fraction and transfer air fraction 


\subsection{A Sample Office Space}

Calculation of the air change effectiveness using the two-region method requires knowledge of the initial design supply and ventilation air flow rates, mixing coefficient, volume fractions, and location of the mixing regions and occupants. To demonstrate the sensitivity of ventilation performance to variations in room air diffusion, the results of a series of calculations follow for a simple office space. In this sample problem, the mixing coefficient and outside air fraction are varied while the volume fraction is held constant at 0.6. The mixing coefficient and volume fractions are application specific and are not likely to be constant when performing these calculations for a real room. Further information for determination of these variables may be found in the work by Rock [1992]. The results presented are for a sample office space with entrainment flow (Figure 2-1) and displacement flow (Figure 2-2) with the following parameters:

$$
\begin{gathered}
\text { Floor area }=1000 \mathrm{ft}^{2}\left(92.9 \mathrm{~m}^{2}\right) \\
\text { Room height }=10 \mathrm{ft}(3.05 \mathrm{~m}) \\
\text { Secondary region to total volume fraction }\left(\mathrm{V}_{S}^{*}\right)=0.6 \\
\text { Occupancy per } 1000 \mathrm{ft}^{2} \text { of floor area }=7 \\
\text { Minimum design outside air per person }=20 \mathrm{CFM}(9.44 \mathrm{Ls})
\end{gathered}
$$

The outside air flow rate is held constant at 140 CFM. The supply air flow rate is varied to yield $20 \%$, $40 \%$, and $100 \%$ initial design percent outside air as shown in Table 5-1. The mixing coefficient, $\beta$, is varied from 1 to 9 by 2 and the results for complete mixing $(\beta=\infty)$ are presented in the following figures.

Table 5-1. Flow rates and initial percentage outside air for the sample office space

\begin{tabular}{lcc}
\hline $\begin{array}{c}\text { Initial Design } \\
\text { Outside Air (0a,62-89) }\end{array}$ & $\begin{array}{c}\text { Total Room } \\
\text { Supply Air (sa) }\end{array}$ & $\begin{array}{c}\text { Initial Design } \\
\text { Point (\%oa) }\end{array}$ \\
\hline 140 CFM (66.1 L/s) & 700 CFM (330.4 L/s) & $20 \%$ \\
140 CFM (66.1 L/s) & 350 CFM $(165.2 \mathrm{~L} / \mathrm{s})$ & $40 \%$ \\
140 CFM (66.1 L/s) & 140 CFM $(66.1 \mathrm{~L} / \mathrm{s})$ & $100 \%$ \\
\hline
\end{tabular}

Figure 5-1 shows generic results for the LTBD/two-region apparent ACH effectiveness models. Results for the displacement flow cases lie at or above the line of complete mixing, while the results for the entrainment flow cases are at or below the complete mixing line. The range of values of the apparent $\mathrm{ACH}$ effectiveness ( $\mathrm{y}$-axis) will vary according to the problem examined. The $\mathrm{x}$-axis is shown in Figures 5-1 through 5-4 in terms of the percentage outside air in the supply air, but the flow rate of outside air could be used as shown in Figure 5-5.

Figure 5-2 shows the apparent $\mathrm{ACH}$ effectiveness as a function of the percentage outside air and mixing coefficient for a minimum 62-89 ventilation of $20 \%$ outside air. This "high-volume" system has a high degree of recirculated air in the supply air. As can be expected, for $20 \%$ outside air and complete mixing $(\beta=\infty), \varepsilon_{A C H}$ is 1 . To evaluate this sample room for compliance with an air change effectiveness standard, the geometry from Figures 3-1 through 3-6 would be determined. If the geometries in Figures 3-1 or 3-5 apply (entrainment flow cases), the curves below $\beta=\infty$ would be used to find the apparent $\mathrm{ACH}$ effectiveness. For example, an air distribution system with very poor performance is selected $(\beta=1)$. To achieve ventilation performance equivalent to that of a completely mixed space, the minimum design percentage outside air would have to be increased from $20 \%$ to about $25 \%$. Because this increase in outside air may carry energy and cost penalties, the designer or evaluator may want to investigate other options to increase the ventilation performance. 


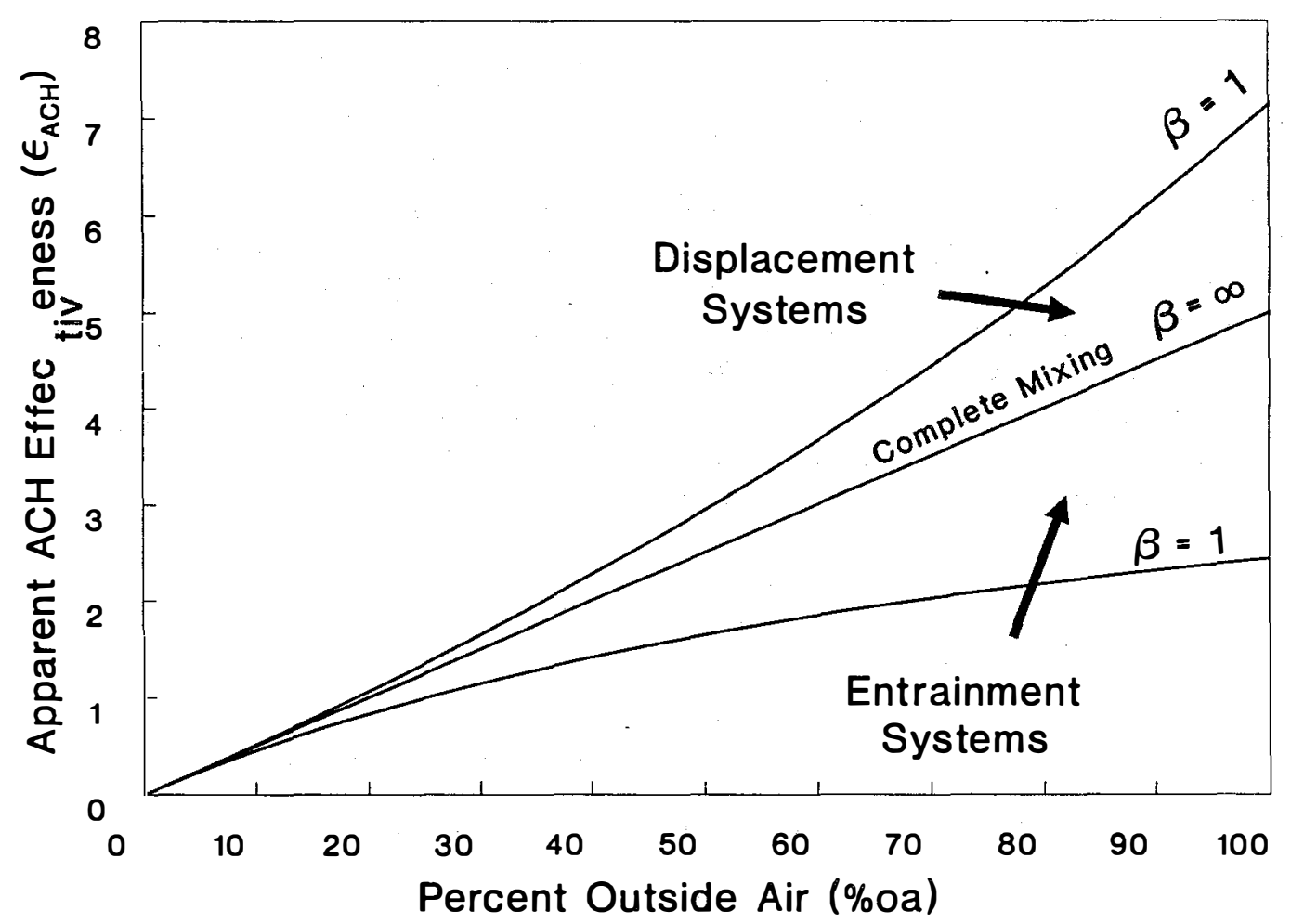

Figure 5-1. Generic layout of the apparent ACH effectiveness as compared to the percentage of outside air for the two-region displacement, complete mixing, and entrainment cases

For the example problem with the geometry shown in Figure 3-4 (displacement flow case), the curves located above the $\beta=\infty$ line in Figure 5-2 would be used. In this geometry with displacement flow, it is an advantage to have little or no mixing between regions. For $\beta=1$, the minimum design percentage outside air could be reduced from $20 \%$ to about $18.5 \%$ and still comply with ventilation standards that use complete mixing as the benchmark. For the two-region geometries shown in Figures 3-2, 3-3, and $3-6$, the ventilation performance is not dependent on the mixing coefficient. For these geometries, the $\beta$ $=\infty$ line is used. Therefore, if the room being designed or evaluated fits one of these three models well, evaluation of the air change effectiveness is not necessary if ASHRAE Standard 62 ventilation rates are implemented.

Figure 5-3 shows the same sample office space with a minimum $62-89$ ventilation of $40 \%$ outside air. This "moderate-volume" system has a moderate degree of recirculated air in the supply air. This example models air distribution systems in which there is usually a high temperature difference between the supply and return air. The figure shows that the cost or credit resulting from geometry and mixing performance is greater than with the minimum design point of $20 \%$ outside air. Figure 5-4 shows a "low-volume" (little or no recirculation) system where the supply air flow rate can equal the minimum outside air flow rate (100\% outside air). This figure shows that the geometries shown in Figures 3-1 and 3-5 (entrainment flow cases) would always fall below the proposed $\varepsilon_{A C H}=1$ standard for $\beta<\infty$. To bring these systems into compliance, high-performance diffusers are needed or the minimum outside air flow rate must be increased substantially as shown in Figure 5-5. Figures 5-2 to 5-5 show also the effect of off-design conditions. For air-handling systems with economizer cycles (where the outside air may exceed the minimum 62-89 percentage of outside air), the increase in air change effectiveness can be observed in Figures 5-2 and 5-3. Also, if the air handler is being operated with less than the minimum 62-89 percentage of outside air, the reduction in air change effectiveness can be determined. 


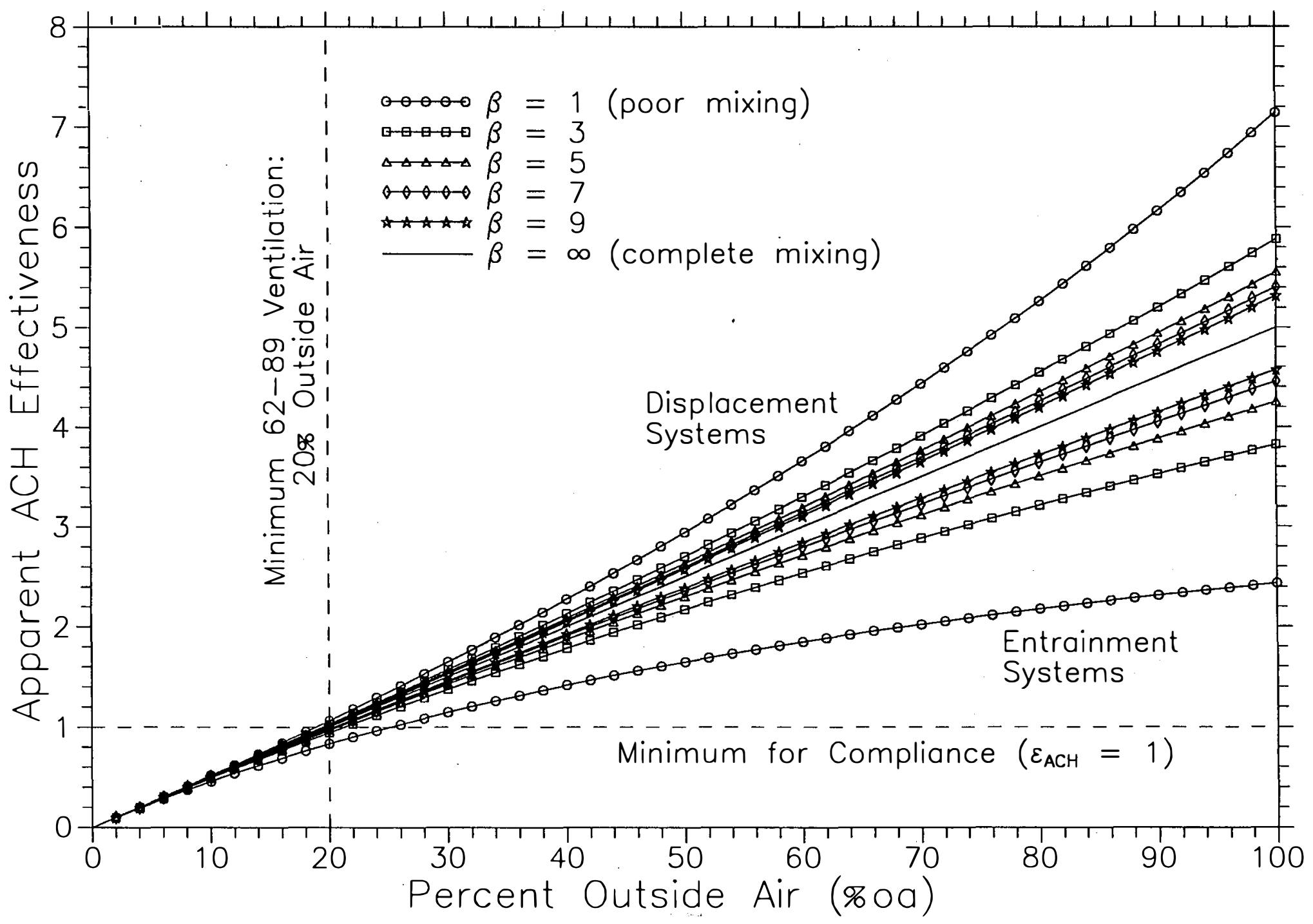

Figure 5-2. Apparent $A C H$ effectiveness $\left(\varepsilon_{A C H}\right)$ as a function of percentage of outside air and mixing coefficient $(\beta)$ for the sample tworegion office space with $20 \%$ outside air at the design conditions 


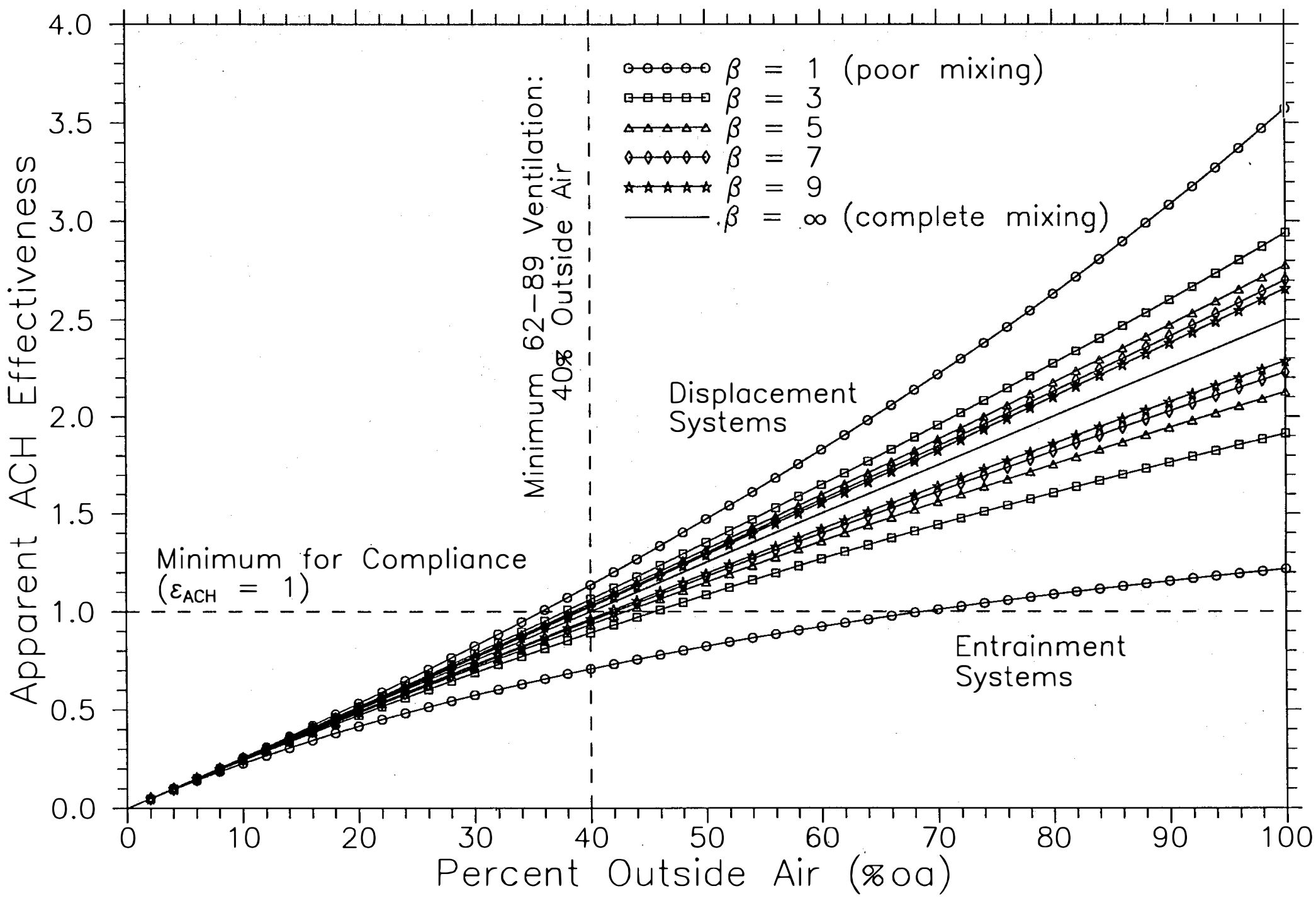

Figure 5-3. Apparent ACH effectiveness $\left(\varepsilon_{A C H}\right)$ as a function of percentage of outside air and mixing coefficient $(\beta)$ for the sample tworegion office space with $40 \%$ outside air at the design conditions 


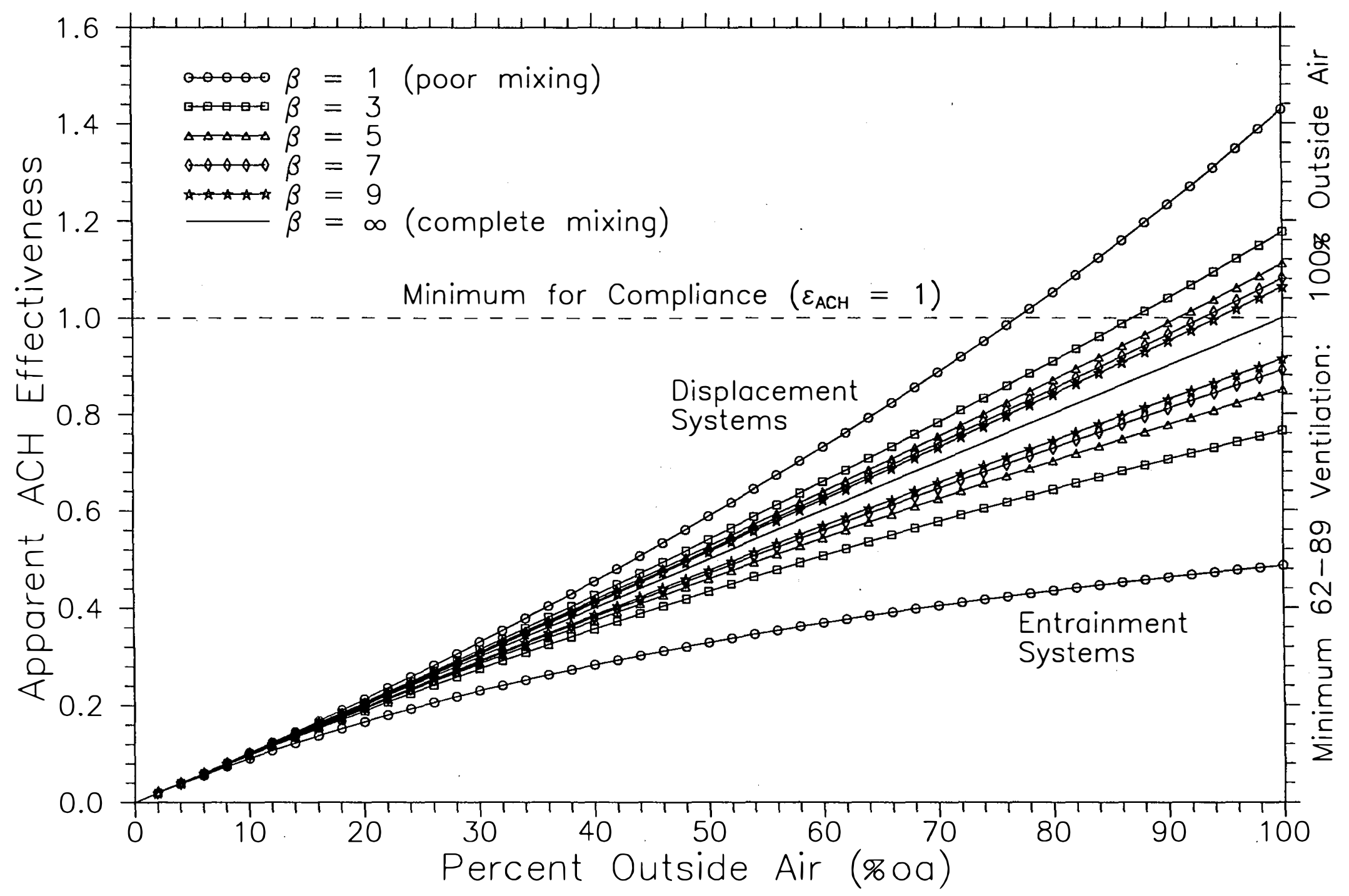

Figure 5-4. Apparent ACH effectiveness $\left(\varepsilon_{A C H}\right)$ as a function of percentage of outside air and mixing coefficient ( $\beta$ ) for the sample tworegion office space with $100 \%$ outside air at the design conditions 




Figure 5-5. Apparent $\mathrm{ACH}$ effectiveness $\left(\varepsilon_{A C H}\right)$ as a function of outside air flow rate for the sample two-region office space with $100 \%$ outside air (no recirculation) 


\subsection{Conclusions and Recommendations}

Usable air change effectiveness standards need to include simple design and testing techniques to ensure the delivery of ventilation air to occupants. If a two-region model is accepted as an adequate compromise between accuracy and simplicity, the work presented here could be used for both design and determination of code compliance. More research is needed to determine the range of application of the two-region models. Rapid, user-friendly computer codes need to be developed using the LTBD/apparent ACH effectiveness approach.

The mixing coefficients $(\beta)$, volume fractions $\left(V^{*}\right)$, and other data required for use of the models presented in this paper are not currently available. The authors are evaluating simple, promising methods for determining these values. Detailed information used by one of these methods is available for simple isothermal jets as a function of diffuser type, location, and other room parameters. Additional research is required for complicated nonisothermal flows. The parameter evaluation methods and supporting data for a variety of applications will be reported in a later paper.

Currently installed high-volume systems (high recirculation rates) will have minimal compliance problems with existing and proposed ventilation standards if proper ventilation rates, such as those included in ASHRAE Standard 62-89, were implemented. Low-volume systems (or once-through, "heat recovery" systems) are much more sensitive to room air distribution when determining the air change effectiveness. Once-through systems will require high-performance diffusers while high-volume (high-recirculation) systems are less dependent on diffuser selection. 


\subsection{Acknowledgments}

This research was sponsored by: the National Renewable Energy Laboratory; the Department of Energy, Office of Buildings Technology, Ventilation Research Program, John Talbott, Program Manager; and the Electric Power Research Institute, Thermal Storage Program, Ron Wendland, Program Manager.

The authors thank Dr. Paul L. Miller of Kansas State University and the multitude of other reviewers whose comments have helped refine this paper. 


\subsection{References}

American Society of Heating, Refrigerating and Air-Conditioning Engineers. ASHRAE Fundamentals Handbook. ASHRAE, Inc., Atlanta, GA (1989a).

American Society of Heating, Refrigerating and Air-Conditioning Engineers. ASHRAE Standard 62-1989, Ventilation for Acceptable Indoor Air Quality. ASHRAE, Inc., Atlanta, GA (1989b).

American Society of Heating, Refrigerating and Air-Conditioning Engineers. ASHRAE Terminology of Heating, Ventilation, Air Conditioning, and Refrigeration. ASHRAE, Inc., Atlanta, GA (1991).

Anderson, R., and M. Mehos. "Evaluation of indoor air pollutant control techniques using scale experiments," ASHRAE IAQ '88, pp. 193-208 (1988).

Janssen, J. E. "Ventilation stratification and air mixing," Indoor Air, vol. 5, pp. 43-48 (1984).

Rock, B. A. Characterization of Transient Pollutant Transport, Dilution, and Removal for the Study of Indoor Air Quality. Ph.D. Dissertation, University of Colorado at Boulder (1992).

Rock, B. A., R. Anderson, and M. J. Brandemuehl. "Modeling of ventilation system performance using Laplace transform techniques, part 1: method," Proceedings of the ASHRAE/CIB Healthy Buildings - IAQ '91 conference, pp. 241-244. ASHRAE, Inc., Atlanta, GA (1991a).

Rock, B. A., R. Anderson, and M. J. Brandemuehl. "Modeling of ventilation system performance using Laplace transform techniques, part 2: applications," Proceedings of the ASHRAE/CIB Healthy Buildings -- IAQ '91 conference, pp. 245-248 (1991b).

Sandberg, M. "What is ventilation efficiency?" Building and Environment, vol. 16, pp. 123-135 (1981).

Sandberg, M., and M. Sjöberg. "The use of moments for assessing air quality in ventilated rooms," Building and Environment, vol. 18, pp. 181-197 (1983).

Seppänen, O. A., W. J. Fisk, J. Eto, and D. T. Grimsrud. "Comparison of conventional mixing and displacement air-conditioning and ventilating systems in U.S. commercial buildings," $A S H R A E$ Transactions, vol. 95, part 2, pp. 1028-1040 (1989).

Skåret, E., and H. M. Mathisen. "Ventilation efficiency -- a guide to efficient ventilation," ASHRAE Transactions, vol. 89, part 2B, pp. 480-495 (1983). 


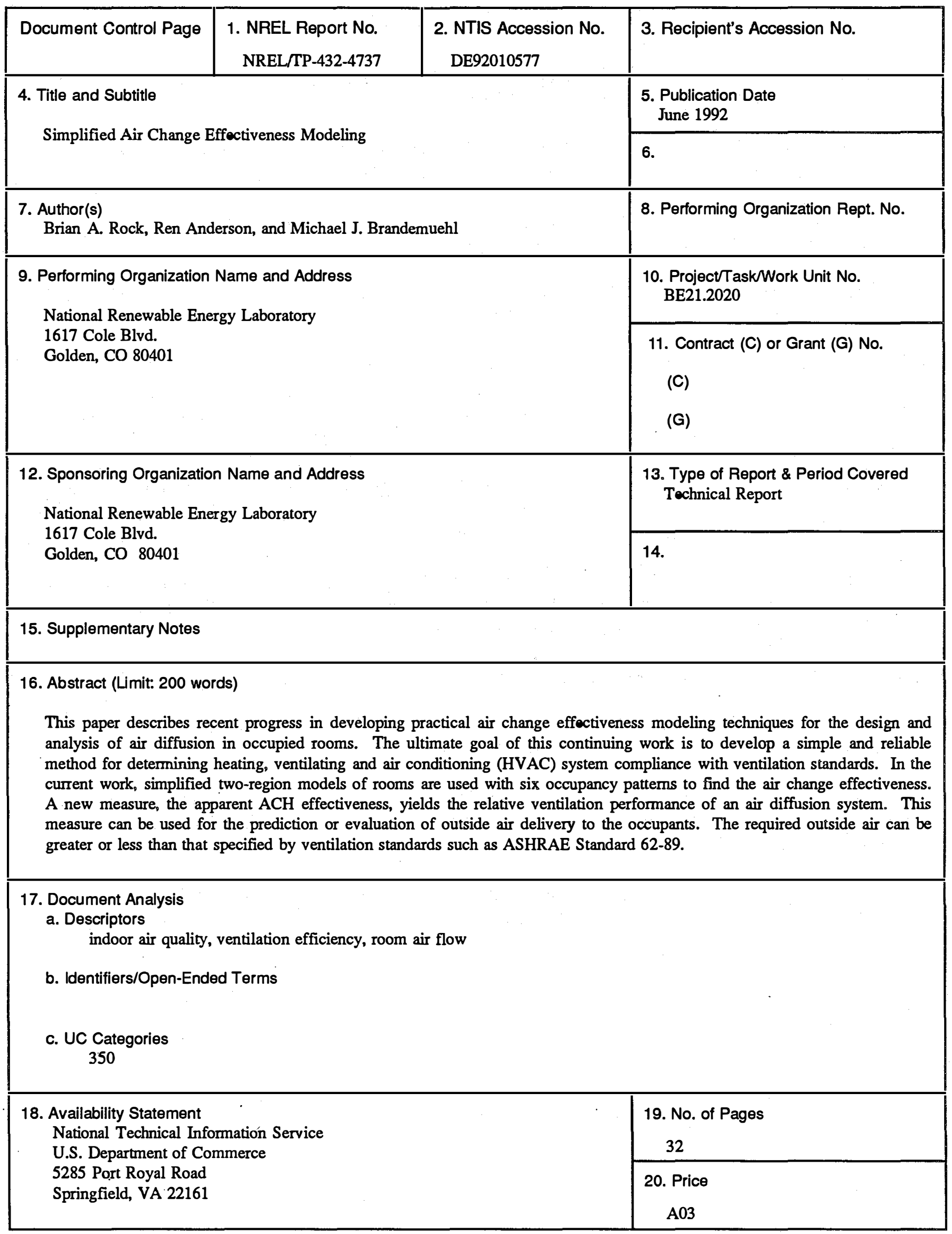

Form No. 0069E (6-30-87) 